\title{
Study on the Correlation Between Passenger Flow Characteristics of Metro Transit and Land Use---Taking Daxing District of Beijing as an Example
}

\author{
Daoyong Li, Jingyi Peng
}

North China University of Technology, No.5 Jinyuanzhuang Road, Shijingshan District, Beijing.100144.

Keywords: Field investigation, District, workable.

\begin{abstract}
The inharmony between the development of new towns and the construction of metro transit has caused the increasingly serious tidal commuter dilemma in megacities. This paper, by means of multivariate data and field investigation, analyzes the correlation between the land use along Daxing District in Bejing and the passenger flow of metro transit, summarizes the reasons why the passenger flows are different in two subway lines at Daxing District, and puts forward a lot of workable suggestions on the surrounding constructions of metro transit stations at Daxing District
\end{abstract}

\section{Introduction}

The coordination construction between metro transit and new town is the key to build multi-center spatial structure. While in reality we cannot achieve the desired goal. A series of city new problems are induced, such as the land development imbalance along the line, new town becoming single lying city, and further aggravating contradiction of traffic flow in central area. Long-time and long-distance commute, and insufficient passenger transport in the peak period have become the focus of the people's livelihood.

Daxing District of Bejing city has a great strategic significance as there are two new towns at the same time. Meanwhile, there are two subway lines in Daxing District, Daxing line and Yizhuang line, which respectively connect Daxing new town and Yizhuang new town, but there are obvious differences in passenger flow. Therefore, these two subway lines selected as the important research objects, by the study on the characteristics between the passenger flow of the lines and all stations and the surrounding land use of station, this paper investigates their correlation, tries to put forward suggestions for the construction of the surrounding station in Daxing District, and provides some certain reference for the construction of other new towns.

\section{Analysis of Passenger Flow Characteristics}

The passenger flow data of Daxing section of Yizhuang line originates from large traffic operation data on March 11, 2015. The data of Daxing section of Daxing line is hard to get, and the flow data are obtained based on the field observation statistics.

\subsection{Analysis of Characteristics of Whole Passenger Flow}

For Daxing section of Yizhuang line, first, there is no unified rule between passenger flow volume of the 6 stations and time. There exists of the peak mismatch among stations. Then, there is no big difference between uptown direction and downtown direction in peak period, the overall transport efficiency of the line is high.

The passenger flow is similar among 10 stations at Daxing section of Daxing line. The peak of incoming passenger flow appears in the morning peak period, and the outgoing passenger flow peak occurs in the evening. Also, there are uneven distribution of bi-directional passenger flow volume in peak periods. The volume in the morning rush period is several times higher in downtown direction than that in uptown direction. It shows the employment direction is obviously pointing to the central city. 


\subsection{Classification of Station Passenger Flow}

\subsubsection{Classification of Daxing Section of Yizhuang Line}

(1) Residential-type station

The change of passenger flow volume of Jiugong station and Yizhuang Bridge station is similar. The incoming peak happens in the morning peak period and outgoing peak occurs in the evening peak period (Figure 1). They are of residential orientation.

(2) Inclined residential-type station

There have two peaks at Yizhuang Cultural Park station, but there are some differences between the two peak heights. In the morning peak period, the incoming peak is more prominent than the outgoing peak in the passenger flow. In the evening peak period, the phenomenon is opposite (Figure 3).

(3) Office-type station

The variation characteristic of passenger flow volume of Wanyuan Street station and Rong Jingdong Street station is similar, which shows it is prominent that incoming happens in the morning peak period and outgoing occurs in the evening peak period (Figure 2). The office orientation is more obvious.

(4) Inclined office-type station

The passenger flow at Rongchang East Street station also has the characteristics of bi-directional peak, but the position of the higher peak and the lower peak has changed. In the morning peak period, the peak of outgoing passenger flow is more significant than that of the incoming. In the evening peak, the phenomenon is opposite (Figure 4).

\subsubsection{Classification of Daxing Section of Daxing Line}

(1) Residential-type station

There appears prominent incoming passenger flow in the morning peak at 8 stations. The prominent outgoing passenger flow occurs at those stations in the evening peak, showing the typical characteristics of the residential-type station. (Figure 5).

(2) Inclined residential-type station

The passenger flow at Tiangongyuan station and Biomedicine Base station has the phenomenon of bi-directional peak. But there are more incoming passengers in the morning peak while the outgoing passenger is more significant in the evening peak (Figure 6), showing inclined residential-type station.
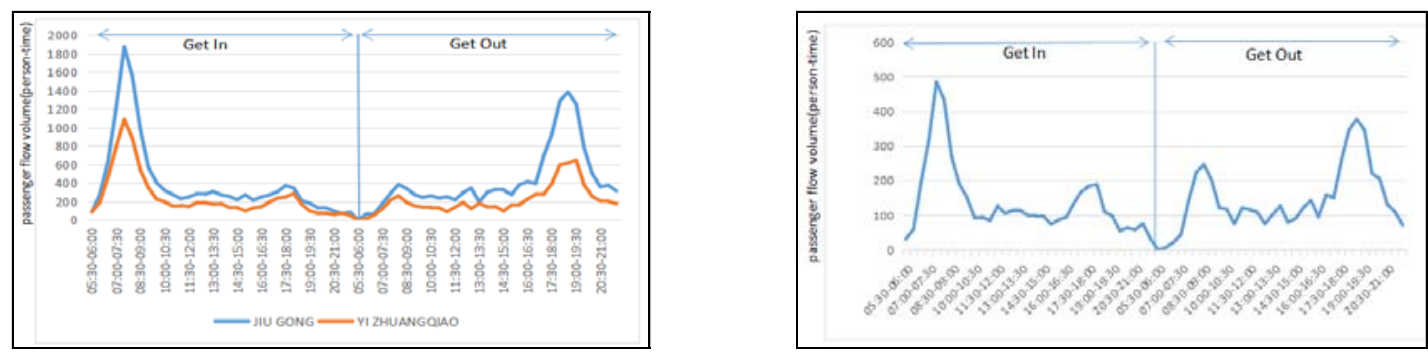

Figure 1. Residential-type stations in L.Yizhuang. Figure 2. Inclined residential-type stations in L.Yizhuang .
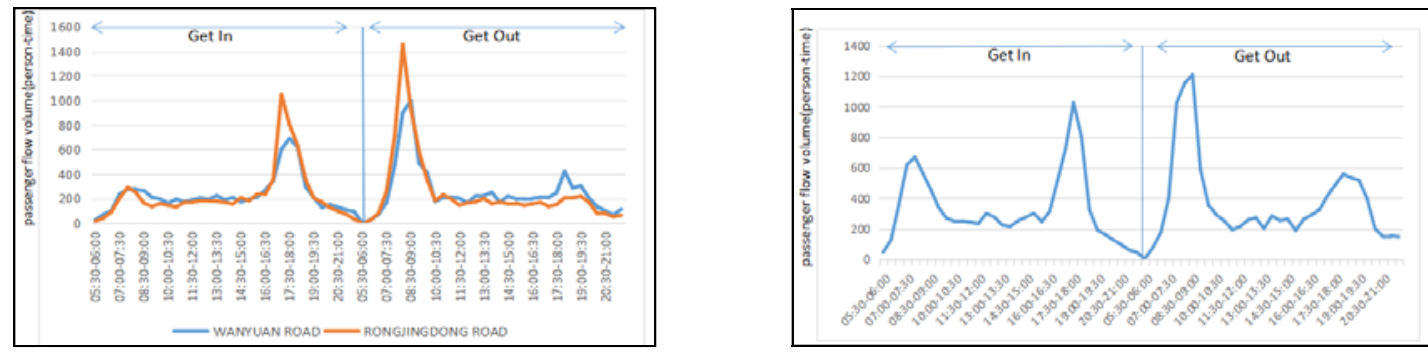

Figure 3. Office-type stations in L.Yizhuang. Figure 4. Inclined office-type stations in L.Yizhuang. 

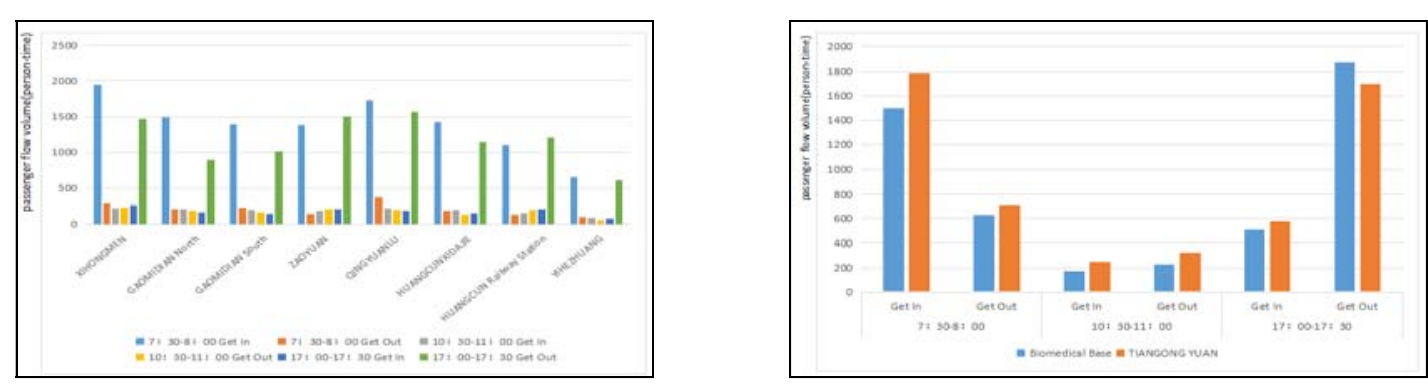

Figure 5. Residential-type stations in L.Daxing. Figure 6. Inclined residential-type stations in

\subsection{Reasons for Difference in Overall Passenger Flow of the Lines}

\section{L.Daxing .}

\subsubsection{Influence of Various Types of Stations and the Layout}

Daxing section of Yizhuang line has various station types, where different type station shows interlaced distribution. There are 2 residential-type stations, 2 office-type stations, 1 inclined residential-type station and 1 inclined office-type station in the line. The layout is residential-type, residential-type, inclined residential-type, office-type, office-type, inclined office-type. The interlaced distribution of each type of station makes residents commuting shorter. There both appear many passengers in two-way traffic at peak time. The type of passenger flow in Daxing section of Daxing line is single, which shows obvious residential orientation. There are 8 residential-type stations and 2 inclined residential type in the line. Station type is single and cannot stagger distribution, which shows obvious tidal flow characteristics of the line.

\subsubsection{Influnce of Endpoint Station Type}

The central city area is the main employment area and has a strong office orientation. The endpoint station in Yizhuang line is also an employment-type station, which makes the passenger flow not only point to the central city, two-way passenger flow is balanced. The endpoint station in Daxing section of Daxing line far away from the city still has a residential orientation, resulting in a strong direction of passenger flow in the city center and longtime of residents overall commute.

\section{Analysis of the Characteristics of Land Use}

\subsection{Data Sources and Research Methods}

The data comes from the actual survey of the stations from February 2017 to July 2017. According to three experience values of $200 \mathrm{~m}, 500 \mathrm{~m}$ and $1000 \mathrm{~m}$ around the station, the study was made to investigate and analyze the land use around the stations. Also, to distinguish the residential and office orientation of the land use, the business-use land and the industrial storage-use land are collectively referred to the office land.

\subsection{Analysis on Current Situstion of Land Use Around the Stations}

At the 6 stations in the Daxing section of Yizhuang line, there is no uniform law of the land use of each station and each circle, and the types are diverse. The whole line also has no strong preference for office and residential land. There are more office areas around Rongchang East Street, Rong Jing East Street and Wanyuan Street stations. While there are more residential land in Yizhuang Cultural Park, Yizhuang bridge and Jiugong stations (Table 1).The land use rate around the stations in Daxing section of Yizhuang line is high, and it is close to $100 \%$. Only the land use rate around Jiugong station is low.

The dominant land at each station and each circle in Daxing section of Daxing line is mostly for residential land, of which each circle of 6 stations is mainly for residential land. Only at Huang Village West Street station and biomedical base station each has a circle leading land not for residential land, but overall is still mainly for residential land in the range of $0-1000 \mathrm{~m}$ (Table 1 ). The overall residence bias of the line is obvious, and the proportion of residential land around the line is far higher than that of the office land. The land use ratio around the stations in Daxing section of Daxing line is relatively low, and there are still 4 available stations. In the $0-200 \mathrm{~m}$ core circle, there is 
a large number of unexploited land which provides favorable opportunities for urban planning land adjustment.

Table 1. The dominant land use around stations in daxing district

\begin{tabular}{|c|c|c|c|c|c|}
\hline Lines & Station & $0-200 \mathrm{~m}$ & $200 \mathrm{~m}-500 \mathrm{~m}$ & $500 m-1000 m$ & $0-1000 \mathrm{~m}$ \\
\hline \multirow{6}{*}{$\begin{array}{c}\text { Daxing section of } \\
\text { Yizhuang line }\end{array}$} & Jiugong & work & Blank land & Residence & Residence \\
\hline & Yizhuang Bridge & Residence & $\begin{array}{l}\text { Residence and } \\
\text { green land }\end{array}$ & $\begin{array}{l}\text { Residence and } \\
\text { green land }\end{array}$ & $\begin{array}{l}\text { Residence and } \\
\text { green land }\end{array}$ \\
\hline & Yizhuang Cutrual Park & Residence & Residence & Green land & Green land \\
\hline & Wanyuan Street & work & work & work & work \\
\hline & Yongjing East Street & Business & work & work & work \\
\hline & Rongchang East Street & work & work & work & work \\
\hline \multirow{10}{*}{$\begin{array}{l}\text { Daxing section of } \\
\text { Daxing line }\end{array}$} & Xihongmen & Residence & Residence & Residence & Residence \\
\hline & Ximidian North & Residence & Residence & Residence & Residence \\
\hline & Gaomidian North & Residence & Residence & Residence & Residence \\
\hline & Zao Park & Residence & Residence & Residence & Residence \\
\hline & Qinyuan Road & Residence & Residence & Residence & Residence \\
\hline & Huangxi West Street & Business & Residence & Residence & Residence \\
\hline & $\begin{array}{l}\text { Huang Village Railway } \\
\text { Sation } \\
\end{array}$ & Residence & Residence & Residence & Residence \\
\hline & Yihezhuang & Village & Village & Blank land & Blank land \\
\hline & Biomedical Base & Residence & Residence & work & Residence \\
\hline & Tiangongyuan & Residence & Residence & work & Work and residenc \\
\hline
\end{tabular}

\section{Correlation Evaluation of Land Use and Passenger Flow}

\subsection{Correlation With Impact Area of Stations (0-1000m)}

There is a great correlation between the land use within the $1000 \mathrm{~m}$ range and the passenger flow characteristics of the station. In the 16 stations of Daxing District, there are 11 sites showing the consistency between the passenger flow characteristics and the dominant land around the stations. The land use of the 9 residential-type stations such as Jiugong station are mainly for residential use. While land around the 2 office-type stations of Wanyuan Street and Rong Jing East Street are mainly for office use.

\subsection{Correlation With Core Area of Stations (0-200m)}

The land use within 200m area around the station has the most direct impact on the passenger flow. The dominant land within 1000m of Tiangongyuan Station is the office land, but the passenger flow characteristics show residential type bias. The main reason is that surrounding the stations the core area gathers a large number of high density and high volume of residential areas, but the mainly office land is at the outside circle, which is almost factory and the volume is low.

\subsection{Correlation With the Area Outside $1000 \mathrm{~m}$ Around Stations}

Daxing line is a typical line of radial suburban line, so tits influence area is wide. It still has certain influence on the $1000 \mathrm{~m}$ beyond the station. The biological medicine base is located in the $1000 \mathrm{~m}$ scope of the station. Its dominant land is for residence. However, due to a large number of industrial and technological companies gathering outside its $1000 \mathrm{~m}$ area, its passenger flow characteristics show certain office tendency.

\subsection{Correlation Evaluation of Traffic Facilities}

The traffic station has a great influence on the passenger flow, which is easy to enhance the residential bias of the station passenger flow. The characteristics of passenger flow in Rongchang East Street show office bias, but the surrounding land has no residential characteristics. For the land use in the scope of $0-1000 \mathrm{~m}$, residential land accounts for only $2 \%$. But unlike other stations, at the exit of Rongchang East Street station a large bus station is set as the bus original station, where many buses gather here to conveniently connect large residential area at the southwest corner of the station. The residences in such areas, where there is no subway available surrounding their residential places, have to meet their commute need by transferring from bus to subway. 


\section{Conclusions and Suggestions}

\subsection{Suggestions on Connection System Around Stations}

The perfect bus connection system is beneficial to reduce the connection time and enlarge the impact area around the station. Therefore, for Daxing line, it is an important way to enhance the station office orientation by properly developing the surrounding land of the affected area as the office land and matching better bus connection system. Especially around Tiangongyuan station and Biomedical Base station there are a large number of employment land, and it is beneficial to make the station more office-oriented as a terminal station, improve the connection system or reform the exit land into bus station land will be beneficial to strengthen the employment guidance. It could help to realize the balance of bidirectional passenger flow. In Daxing section of Yizhuang line, residents spend longer time from station to residential place. It will reduce commute time if the connection system is improved around the station.

\subsection{Suggestions on Land Use Around Stations}

The core impact area has the greatest influence on the station passenger flow. We should make full use of the station within the scope of $0-200 \mathrm{~m}$ to build land, develop it with high intensity, and reform it into a high volume commercial office land.

The land use and the intensity of land development around the station within the $0-1000 \mathrm{~m}$ range have a great impact on its passenger flow. In the land control, we should cooperate with its location and its surrounding land, appropriately increase business land, industrial land and logistics warehousing land.

Also, Improve the status of tidal passenger flow with the adjustment of the $1000 \mathrm{~m}$ area outside the station. As a suburban line, Daxing line has a wide influence and still has a certain influence on the range of outside $1000 \mathrm{~m}$ of the station. Therefore, we should consider its own conditions, cooperate with the development of the industry, and consider to strength the construction of office land outside the scope of $1000 \mathrm{~m}$ which enhances the employment orientation of the passenger flow.

\section{Acknowledgements}

The corresponding author of this paper is Jingyi Peng. The article is based on the support of following fund project: The National Natural Science Youth Fond Project "Study on the mechanism of spatial response in the rail transit corrider based on dynamic balance”, the number is 51608009; the Beijing Talent Training Program "Transformation and reconstrution of the outskirts of Beijing in the context of the coordinated development of Beijing-Tiajin-Hebei region", the number is 2015000020124 G019 and the Research Launch Fund Project of North China University of Technology "Study on the optimization of urban spatial structure based on the rail transit.

\section{References}

[1]. Daoyong Li, Dong Jia and Lijian Ren. The international experience and inspiration of the strategic transformation of metropolis space under the background of multicenter -- Based on the perspective of metro transit and new town construction [B]; Modern urban research(2017).

[2]. Haixiao Pan, Chunyang Ren and Liaoyun Yang. An empirical study of the influence of Shanghai metro transit to the land use of station area [A]; Discipline of urban planning (2007).

[3]. Jing Xue and Meiqing Zhang. The development problems of the network of Beijing city metro transit and research on countermeasures -- Based on the background of the separation of living and working places [A]; Journal of Beijing Jiaotong University (2016).

[4]. Qin Yin, Bin Meng and Liying Zhang. Based on the passenger flow characteristics of the type identification of Beijing subway station [J]; Progress in geo science (2016). 